\title{
Evaluation of Vascular Morphological Changes in The Superficial and Deep Retinal Plexuses by Optical Coherence Tomography Angiographyin Cases of Acute Phase Branch Retinal Vein Occlusion Ahmad El-Sayed Hudieb \\ Department of Ophthalmology, Faculty of Medicine, Al-Azhar University, Cairo, Egypt
}

\begin{abstract}
Background: Retinal vein occlusion (RVO) is the second most common retinal vascular disease after diabetic retinopathy and an important cause of visual morbidity and blindness

Aim of the work: was to detect if there are diagnostic signs in the two intra retinal layers superficial network layer and deep network layer by Optical coherence tomography angiography (OCT-A) to diagnose branch retinal vein occlusion.

Patients and Methods: an observational cross-sectional study included a total of ten patients with branch retinal branch retinal vein occlusion of recent onset within three months attending at the Ophthalmology Department AlAzhar University Hospitals, Cairo. Demographic data such as age, gender, sex and hypertensive history were obtained. A detailed evaluation of cases including complete anterior segment evaluation and posterior segment evaluation was done. OCT-A and fluorescein angiography (FA) were used to study the vascular morphological changes in the branch retinal vein occlusion (BRVO)area.

Results: As regarding 5 disc area of retinal ischemia FA detected ischemia in 2 cases (20\%), detected no ischemia in one case $(10 \%)$ and was not able to evaluate ischemia in 7 cases $(70 \%)$ compared to OCT-A, that detected the ischemia in the superficial retinal plexus (SCP) in 4 cases (40\%) and detected no ischemia in 6 cases (60\%), but it detected the ischemia in the deep retinal plexus (DCP) in 6 cases $(60 \%)$ and detected no ischemia in 4 cases (40\%). Conclusion: It could be concluded that that OCT-A was superior to FA in detection of macular ischemia, macular ischemia detected by OCT-A had stronger negative relation with V.A. than macular ischemia detected by FA and retinal ischemia in the DCP was more evident than that of SCP by OCT-A.
\end{abstract}

\section{INTRODUCTION}

Retinal vein occlusion (RVO) is the second most common retinal vascular disease after diabetic retinopathy and an important cause of visual morbidity and blindness ${ }^{(\mathbf{1})}$. Retinal vein occlusion may develop at different sitesand to varying extent. Depending on the location of occlusion it can be classified into occlusions of central vein, hemi central vein, major branch vein and macular branch vein ${ }^{(2)}$. Fluorescein angiographic (FA) assessment is an important tool for an adequate evaluation of the disease severity and for proper classification between the two types of (RVO), ischemic and non-ischemic (3). However, FA cannot separately visualize the intraretinal structures of major capillary networks; the images of superficial and deep capillaries overlap, so 2 of the 3 major capillary networks (superficial retinal, deep retinal and chorio capillaries) do not appear to be imaged well despite the retina being a nearly transparent structure ${ }^{(4)}$.

OCTA, in comparison, is a non-invasive technique that acquires volumetric angiographic information without the use of dye. Each three-dimensional scan set takes approximately six seconds to obtain. The en-face images obtained can then be scrolled to visualize individual vascular plexuses and segment the inner retina, outer retina, choriocapillaris, or other areas of interest ${ }^{(5)}$. The aim of this study was to detect the vascular morphological changes in the branch retinal vein occlusion area in both the superficial and the deep retinal network layers by OCT-A in cases of acute onset BRVO.

\section{PATIENTS AND METHODS}

This observational cross-sectional study included a total of ten patients to detect the vascular morphological changes in the branch retinal vein occlusion area of recent onset within three months, in both the superficial and the deep retinal network layers by OCT-A in cases of acute onset BRVO. Patients had attended at the Ophthalmology Department, Al-Azhar University Hospitals, Cairo, Egypt.

Approval of the ethical committee and a written informed consent from all the subjects were obtained.

This study was conducted between January 2016, and December 2017.

Each case was subjected to a detailed ocular examination. This assessment included uncorrected visual acuity (UCVA), refraction (automated) and then best corrected visual acuity (BCVA), Intraocular pressure (IOP) measurement using applanation tonometer, Anterior segment slit-lamp examination, Posterior segment slit-lamp examination by +78 lens an, color photography fundus examination Fundus 
Fluorescein angiography (FFA) and OCT-A was performed using (Topcon OCT Triton), $6 \times 6 \mathrm{~mm}$ scan was taken centered on the fovea in all cases.

\section{Statistical analysis}

Data were collected, revised and statistically analyzed using an IBM personal computer with Statistical Package of Social Science (SPSS) version 22 (SPSS, Inc, Chicago, Illinois, USA) where the following statistics were applied.

The quantitative data were presented as mean, standard deviations and ranges when their distribution found parametric and qualitative data were presented as number and percentages a $\mathrm{P}$ value of $<0.05$ was considered significant statistically.

\section{RESULTS}

This study was conducted on 10 eyes of 10 patients ( 3 males $30 \%$ and 7 females $70 \%$ ) (Table1)

Table (1): Socio-demographic data of included patients

\begin{tabular}{|l|l|l|}
\hline Sex & N & \% \\
\hline \hline Male & 3 & 30 \\
\hline Female & 7 & 70 \\
\hline Total & 10 & 100 \\
\hline
\end{tabular}

The mean age of the patients was $50.40 \pm 13.53$ years (Range 24 to 71), The mean time from onset to imaging was $12.40 \pm 4.90$ days (Range $5-20$ ), The mean IOP of the patients was $12.50 \pm 3.72 \mathrm{mmHg}$ (Range $8-20$ ), The mean V.A. of the patients was $0.074 \pm 0.075$ (Range $0.003-0.250)$ (Table2)
Table (2): General clinical data.

\begin{tabular}{|l|l|l|}
\hline \multicolumn{1}{|l|}{} & Range & Mean \pm S. D \\
\hline \hline Age (years) & $24-71$ & $50.40 \pm 13.53$ \\
\hline $\begin{array}{l}\text { Onset of } \\
\text { complain (days) }\end{array}$ & $5-20$ & $12.40 \pm 4.90$ \\
\hline IOP (mmHg) & $8-20$ & $12.50 \pm 3.72$ \\
\hline VA (decimal) & $0.003-$ & \\
& 0.250 & $0.074 \pm 0.075$ \\
\hline
\end{tabular}

5 cases (50\%) were hypertensive and 5 cases (50\%) were not hypertensive (Table 3 ).

Table (3): Classification of cases according to hypertension as a risk factor.

\begin{tabular}{|l|l|l|}
\hline Hypertension & N & \% \\
\hline \hline Yes & 5 & 50 \\
\hline No & 5 & 50 \\
\hline Total & 10 & 100 \\
\hline
\end{tabular}

Mathematically, 5-disc diameter area by FA equal to $(8.85-11.35) \mathrm{mm}^{2}$, this area corresponds to $3 \times 3 \mathrm{~mm}^{2}$ of OCT-A scan (a quadrant of 6x6 OCT-A scan)

In current study, the significant macular ischemia by OCT-A in BRVO means that there is an area of macular ischemia extends from the FAZ equal to $9 \mathrm{~mm}^{2}$ or $3 \times 3$ $\mathrm{mm}^{2}$ (a quadrant of $6 \times 6$ scan), Even if there is macular edema within this area.

The macular ischemia was revealed in 2 cases by FA, but the significant macular ischemia was revealed in 4 cases in SCPand in 6 cases in DCP by OCT-A which included the ischemic 2 cases detected by FA.

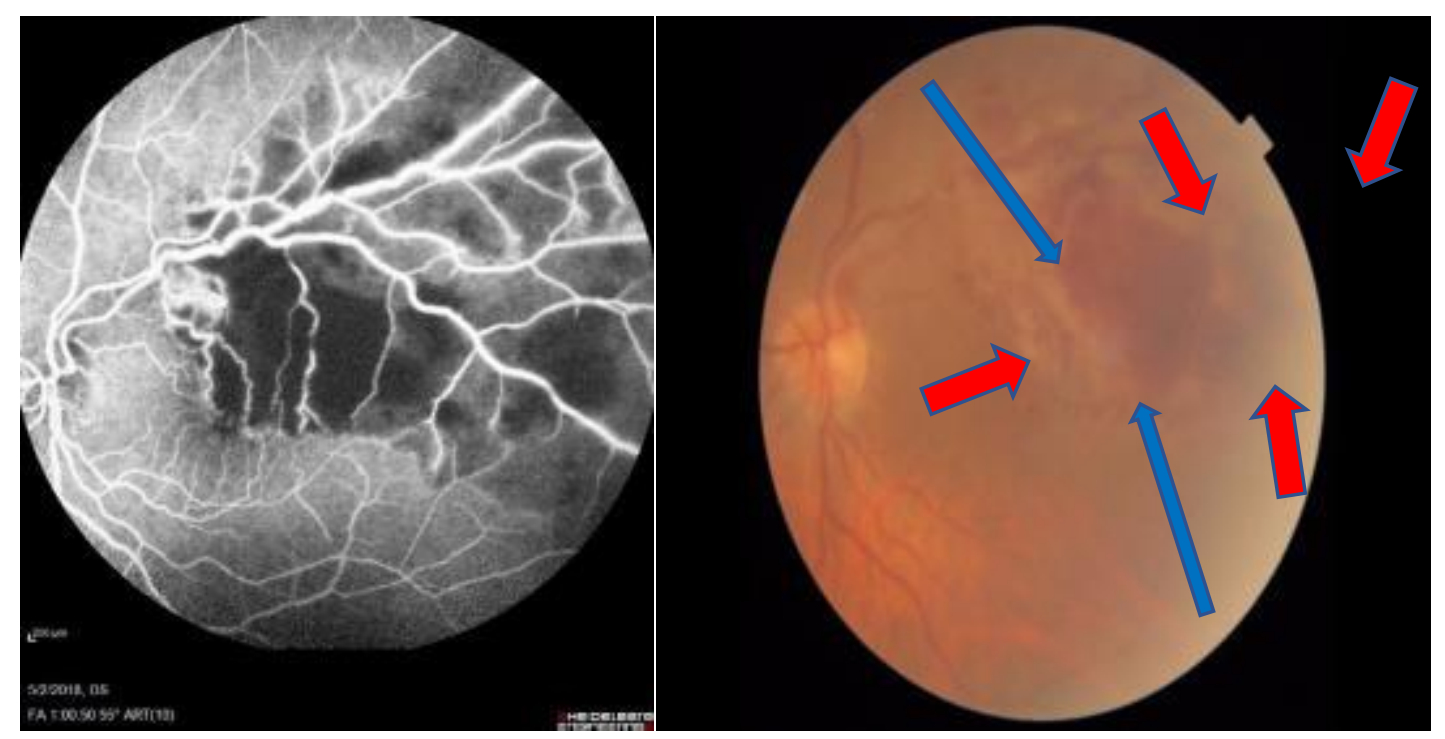




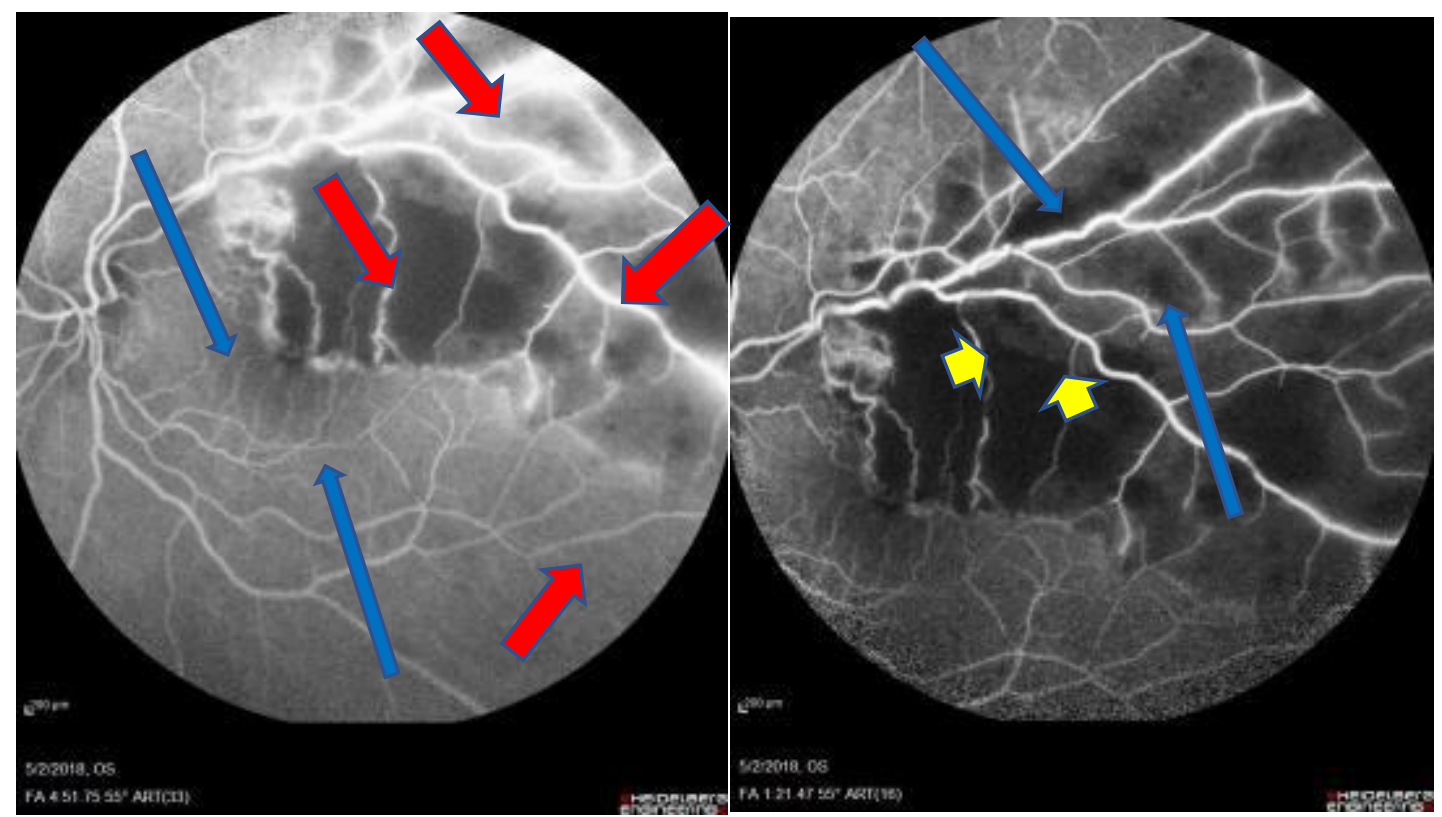

Figure (1): FA of upper temporal BRVO of left eye showing retinal ischemia more than 5disc diameter so described as ischemic type, ischemic area (short red arrow), masking by intraretinal hemorrhage (long blue arrow), FAZ involved macular edema (yellow arrow head).

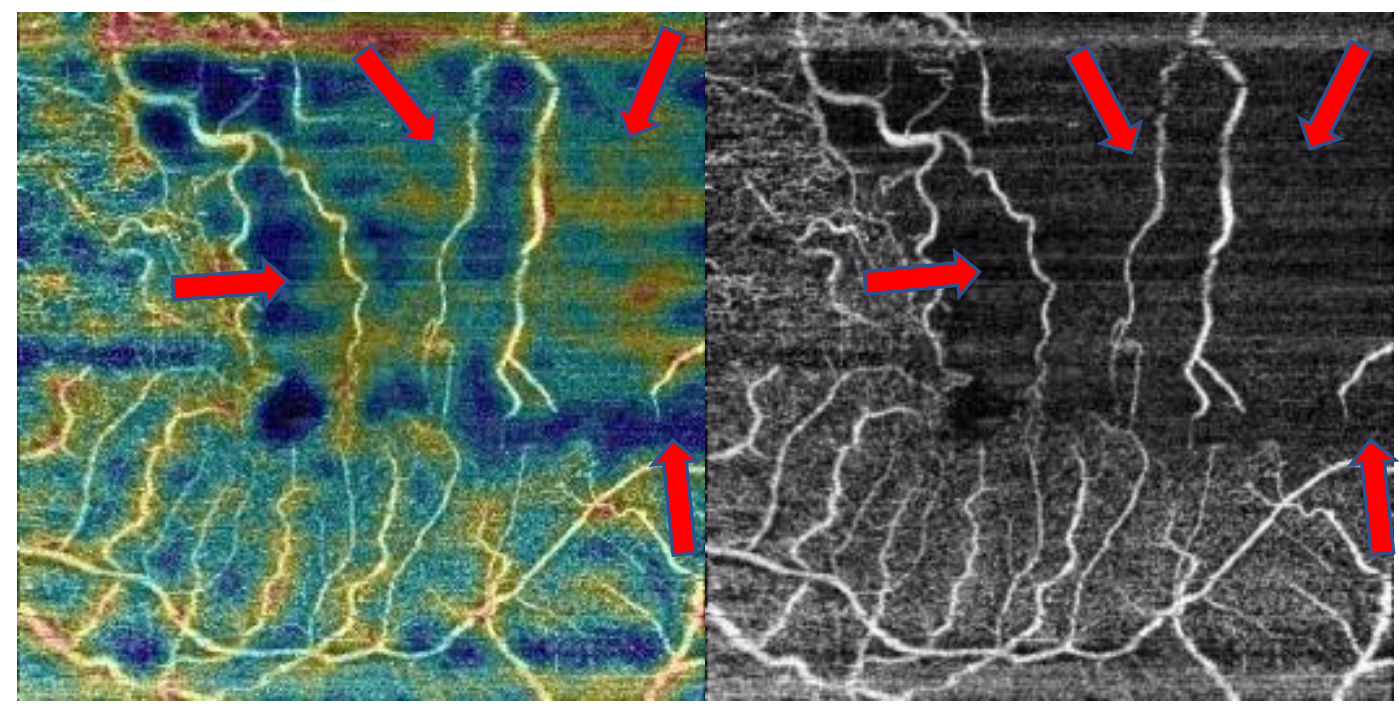

Figure (2): SCP and its color map corresponding to (figure1) showing significant macular ischemia at area of distribution of the occluded vein. ischemic area (red arrow). 


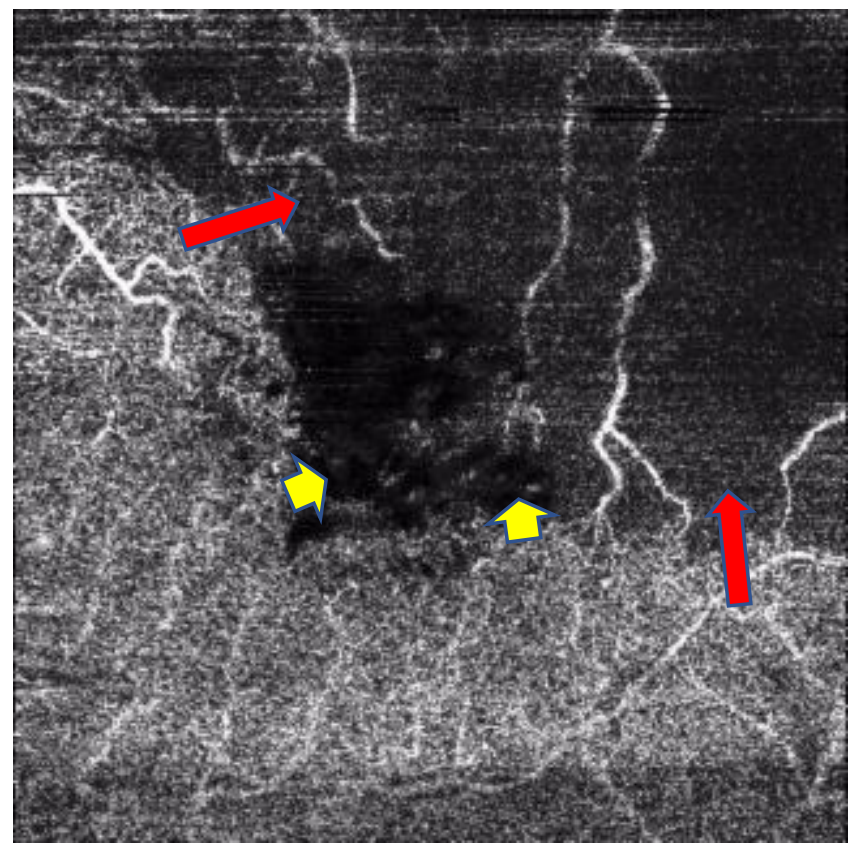

Figure (3): DCP corresponding to (figure 1) showing significant macular ischemia at area of distribution of the occluded vein. ischemic area (red arrow), macular edema (yellow arrow head).
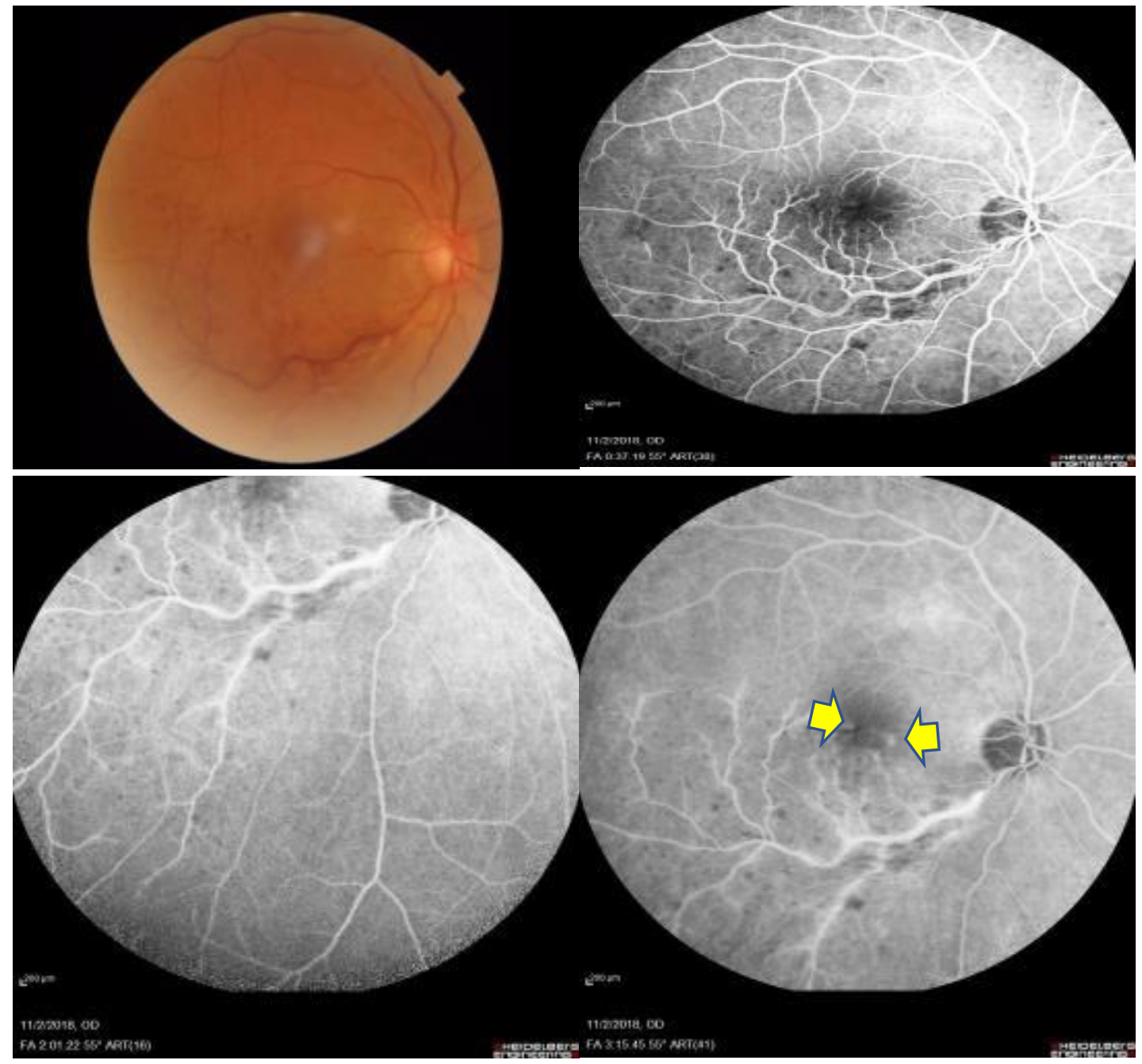

Figure (4): FA of lower temporal BRVO of right eye showing no retinal ischemia so described as non-ischemic type. FAZ involved macular edema (yellow arrow head). 


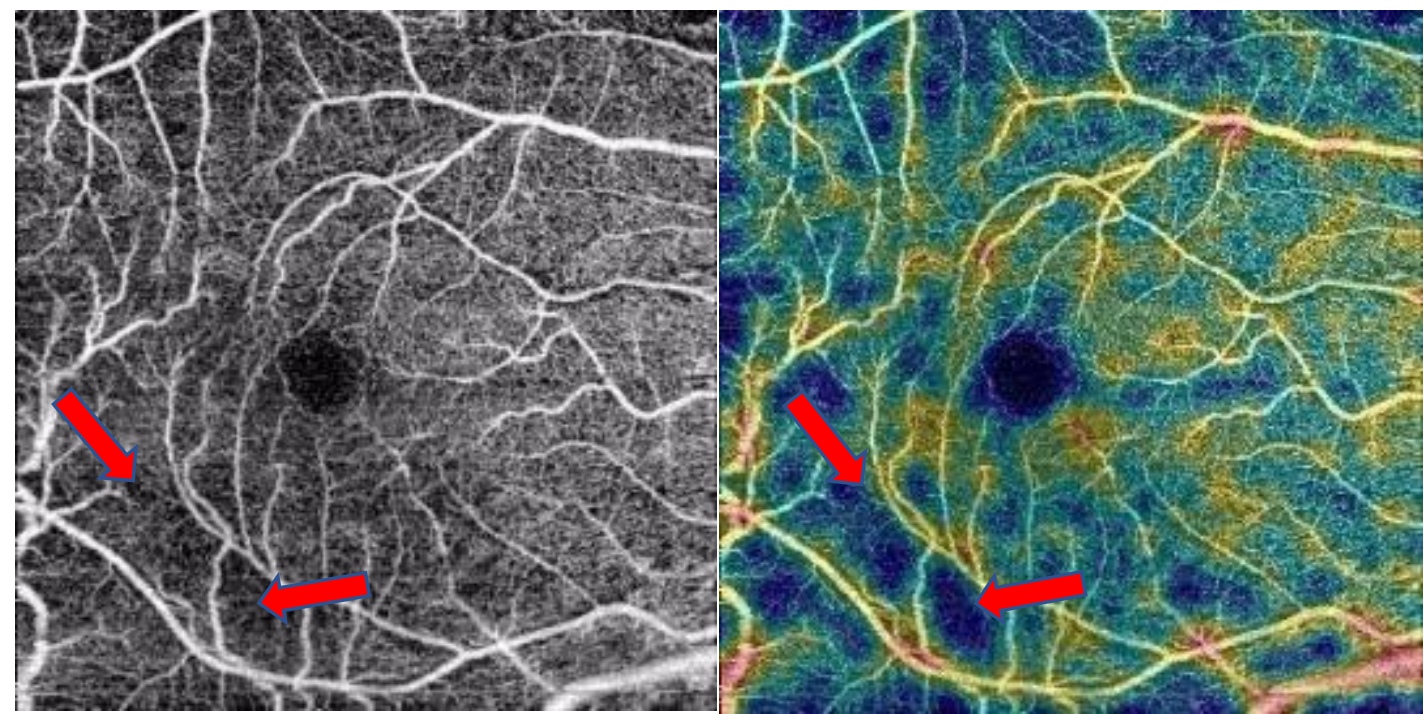

Figure (5): SCP and its color map corresponding to (figure4) showing non-significant macular ischemia at area of distribution of the occluded vein (ischemic area is less than 5-disc area). ischemic area (short red arrow).

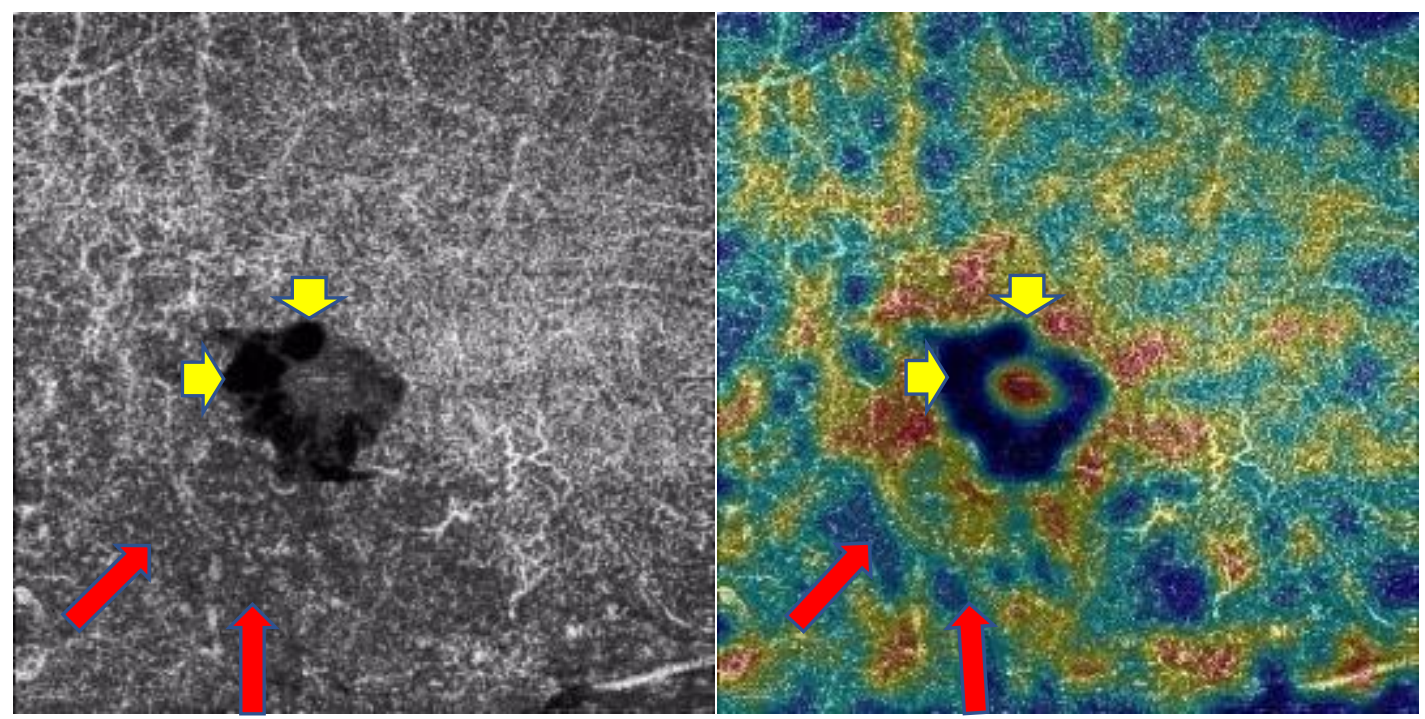

Figure (6): DCP and its color map corresponding to (figure 4) showing non-significant macular ischemia at area of distribution of the occludedvein (ischemic area is less than 5-disc area),ischemic area (red arrow), macular edema (yellow arrow head). 


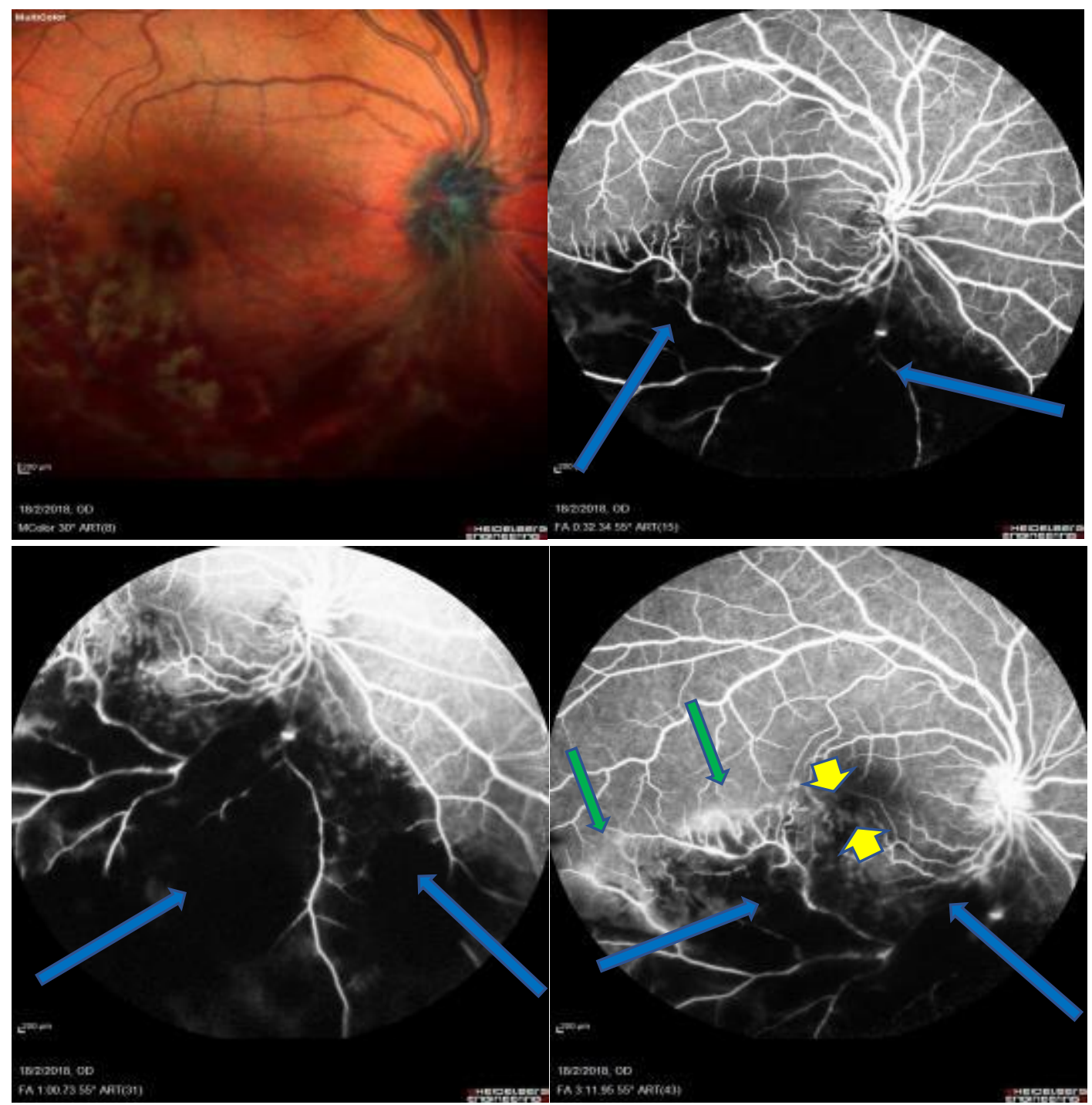

Figure (7): FAof lower temporal BRVO of right eye showing retinal masking by hemorrhage so described as undetermined type. masking by dye leaking (short green arrow), masking by intraretinal hemorrhage (long blue arrow), FAZ involved macular edema (yellow arrow head).

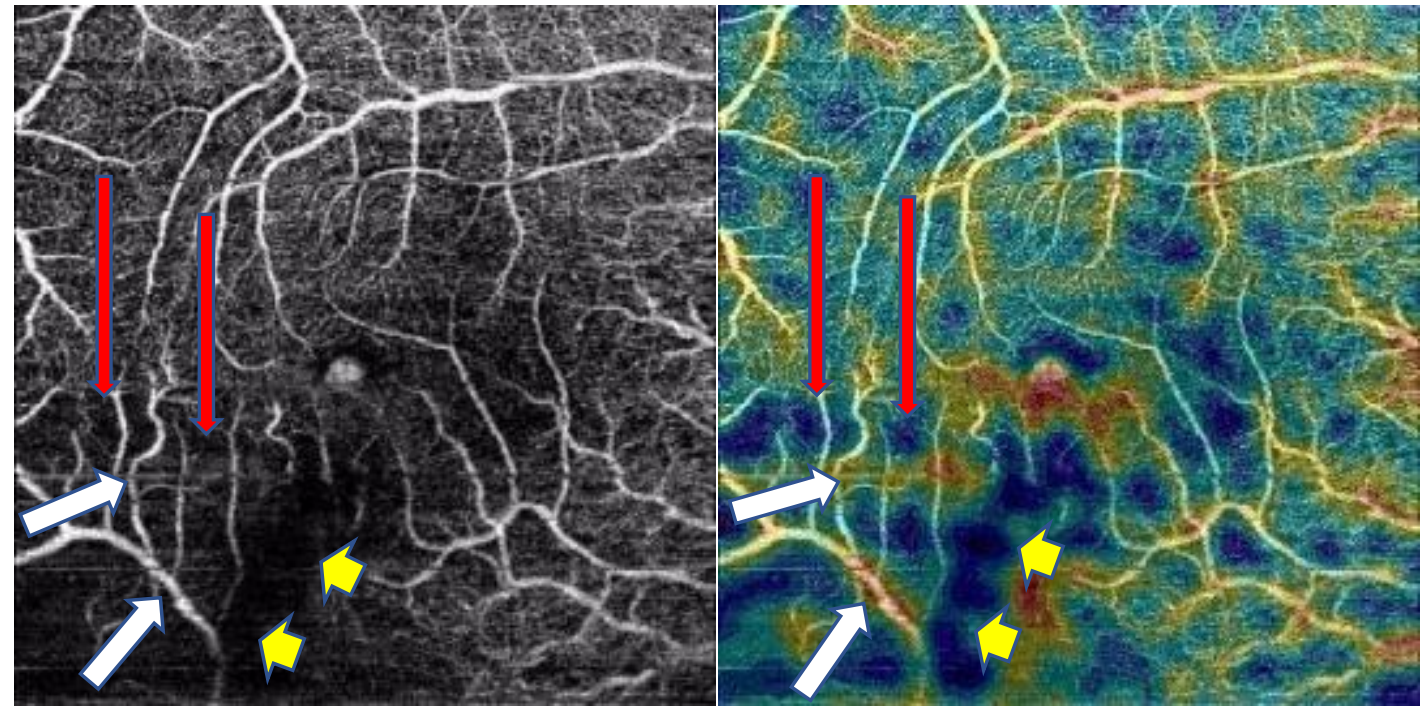

Figure (8): SCP and its color map corresponding to (figure 7) showing significant macular ischemia at area of distribution of the occluded vein. ischemic area (long red arrow) macular edema (yellow arrow head), healthy area (short white arrow). 


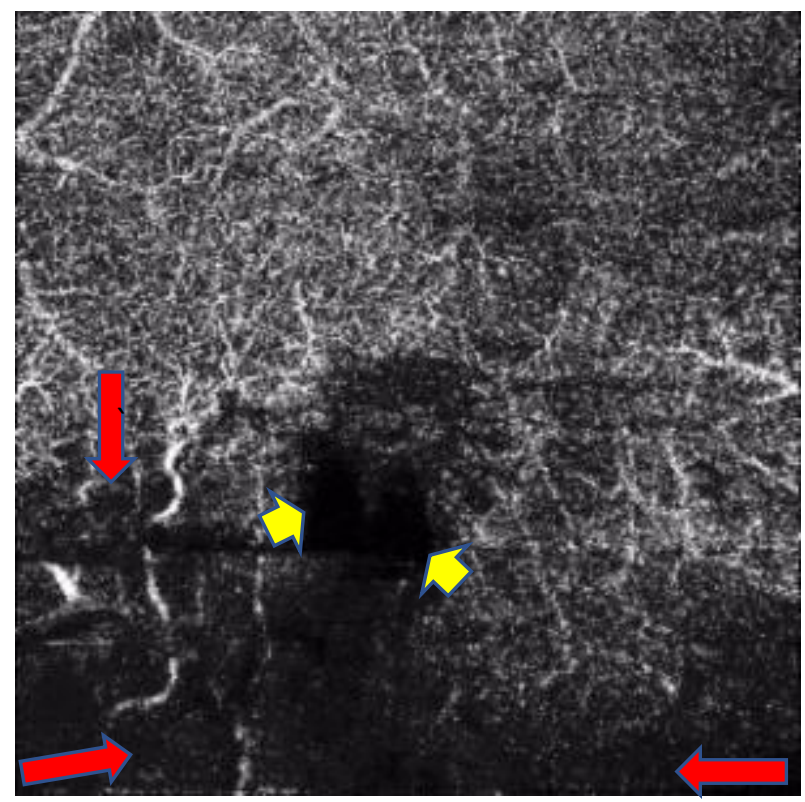

Figure (9): DCP corresponding to (figure 7) showing significant macular ischemia at area of distribution of the occluded vein. ischemic area (red arrow) macular edema (yellow arrow head).

The relation between FA and SCP by OCT-A in detection of significant macular ischemia was highly statistically significant(Table 4), this demonstrated that OCT-A is superior to FA especially when retina is obscured by extensive hemorrhage in cases of BRVO.

Table (4): The relation between FA and OCT-A in detection of significant macular ischemia in SCP after classification of cases according to ischemic condition

\begin{tabular}{|l|l|l|l|l||}
\hline \multirow{2}{*}{} & \multicolumn{2}{|l|}{ FFA } & \multicolumn{2}{l|}{$\begin{array}{l}\text { significant macular ischemia } \\
\text { in SCP by OCT-A }\end{array}$} \\
\cline { 2 - 5 } & N & \% & N & \% \\
\hline Ischemic & 2 & 20 & 4 & 40 \\
\hline Non-ischemic & 1 & 10 & 6 & 60 \\
\hline Undetermined & 7 & 70 & 0 & 0 \\
\hline Total & 10 & 100 & 10 & 100 \\
\hline Fisher's Exact Test & 11.241 & & & \\
\hline P. value & $0.004 *$ & & & \\
\hline
\end{tabular}

The macular ischemia was revealed in 2 cases by FA, but the significant macular ischemia was revealed in 6 cases in DCP by OCT-A which included the ischemic 2 cases detected by FA.

The macular ischemia was revealed in 2 cases by FA, but the significant macular ischemia was revealed in 6 cases in DCP by OCT-A which included the ischemic 2 cases detected by FA.

The relation between FA and OCT-A regarding DCP in detection of significant macular ischemia was highly statisticallysignificant (table 5), this demonstrated that OCT-A is superior to FA especially when retina is obscured by extensive hemorrhage in cases of BRVO. 
Table (5): The relation between FA and OCT-A regarding DCP in detection of significant macular ischemia after classification of cases according to ischemic condition.

\begin{tabular}{|l|l|l|l|l|}
\hline \multirow{2}{*}{} & \multirow{4}{*}{ FA } & \multicolumn{2}{|l|}{$\begin{array}{l}\text { Significant macular } \\
\text { ischemia in DCP by } \\
\text { OCT-A }\end{array}$} \\
\cline { 2 - 6 } & N & \% & N & \% \\
\hline Ischemic & 2 & 20 & 6 & 60 \\
\hline Non-ischemic & 1 & 10 & 4 & 40 \\
\hline Undetermined & 7 & 70 & 0 & 0 \\
\hline Total & 10 & 100 & 10 & 100 \\
\hline Fisher's Exact Test & 10.802 & & \\
\hline P. value & $0.005^{*}$ &
\end{tabular}

A statistically significant difference was found between mean visual acuity in cases with macular ischemia detected by FA and mean visual acuity in cases in which FA didn't detect macular ischemia (Table 6),

A negative relation was found between mean visual acuity and macular ischemia detected by FA(Figure52).

Table (6): Relation between visual acuity and macular ischemia detected by FA

\begin{tabular}{|c|c|c|c|c|c|c|}
\hline & \multicolumn{3}{|l|}{ FA } & \multirow{2}{*}{ F. test } & \multirow{2}{*}{ P. value } \\
\hline & & Ischemic & Non-ischemic & Undetermined & & \\
\hline \multirow{3}{*}{ VA } & Range & $0.016-0.050$ & $0.25-0.25$ & $0.003-0.1$ & \multirow{3}{*}{8.366} & \multirow{3}{*}{$0.014 *$} \\
\hline & 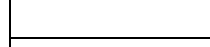 & & & & & \\
\hline & Mean \pm SD & $0.033 \pm 0.024$ & $0.25 \pm 0.0$ & $0.046 \pm 0.05$ & & \\
\hline
\end{tabular}

Although a negative relation was found between mean visual acuity and significant macular ischemia detected by OCT-A in the SCP(Table 7).

Table (7): Relation between significant macular ischemia in the SCP detected by OCT-A and VA.

\begin{tabular}{|c|c|c|c|c|c|}
\hline & & \multicolumn{2}{|c|}{$\begin{array}{l}\text { significant macular ischemia in } \\
\text { SCP by OCT-A }\end{array}$} & \multirow{2}{*}{ T. test } & \multirow{2}{*}{ P. value } \\
\hline & & Ischemic & Non-ischemic & & \\
\hline \multirow{2}{*}{ VA } & Range & $0.003-0.10$ & $0.008-0.250$ & \multirow{2}{*}{1.258} & \multirow{2}{*}{0.294} \\
\hline & Mean \pm SD & $0.042 \pm 0.09$ & $0.096 \pm 0.087$ & & \\
\hline
\end{tabular}


a statistically significant difference was found between mean visual acuity in cases with significant macular ischemia detected in DCP by OCT-A and mean visual acuity in cases with non-significant macular ischemia (Table).

There is anegative relation between the mean visual acuity and the significant macular ischemia in the DCP detected by OCT-A(Table 8).

Table (8): Relation between significant macular ischemia in the DCP detected by OCT-A and VA.

\begin{tabular}{|c|c|c|c|c|c|}
\hline & & \multicolumn{2}{|c|}{$\begin{array}{l}\text { Significant macular ischemia in } \\
\text { DCP by OCT-A }\end{array}$} & \multirow{2}{*}{ T. test } & \multirow{2}{*}{ P. value } \\
\hline & & Ischemic & Non-ischemic & & \\
\hline \multirow{2}{*}{ VA } & Range & $0.003-0.10$ & $0.1-0.250$ & \multirow{2}{*}{8.969} & \multirow{2}{*}{$0.017^{*}$} \\
\hline & Mean \pm SD & $0.032 \pm 0.037$ & $0.138 \pm 0.075$ & & \\
\hline
\end{tabular}

\section{DISCUSSION}

In our study the prevalence of hypertension was $50 \%$, this consistent with Johnston et al.$^{(6)}$, who reported that the prevalence of hypertension in patients with BRVO is $37-79 \%$ in various series.

In our study, by OCT-A we found that most major BRVOs were ischemic. the same results as those reported ${ }^{(7)}$, But by FA we found that non-ischemic BRVOs are more common. The same results were reported by Liu and $\mathbf{X u}{ }^{(8)}$. This accentuated the role of OCT-A in detection of macular ischemia in acute onset BRVO especially when the retina is obscured by retinal hemorrhage.

In this study we found that FA was not able to evaluate retinal ischemia due to hemorrhage in $70 \%$ of cases. Hayreh et al. ${ }^{(9)}$ found that in early RVOs, FA wasn't able to evaluate retinal ischemia in more than $1 / 3$ of the studied cases.

Although there was no difference in numbers of ischemic cases detected by OCT-A in SCP and DCP, the cases showed evident difference in size of the ischemic macular area and evident difference in VA, so we stated a standard of the significant macular ischemia by OCTA.

in our study we defined a standard of the significant macular ischemia by OCT-A as an area of macular ischemia extending from the FAZ equal to $3 \times 3$ $\mathrm{mm}^{2}$ or a quadrant of $6 \times 6$ scan even there is macular edema within this area.

when we compared between SCP and DCP in detection of the significant macular ischemia by OCT-A according to our standard, OCT-A showed significant macular ischemia in DCP in 6 cases, but it showed significant macular ischemia in SCP in only 4 cases.
These results the same as Coscas et $\boldsymbol{a l} .{ }^{(\mathbf{1 0})}$ who reported that OCT-A showed ischemia in deep plexus more than superficial plexus.

In the current study, we observed that the OCT-A is superior to FA in evaluation of macular ischemia in both SCP and DCP. The same results were reported by Suzuki et al. ${ }^{(11)}$ Who reported that OCT-A is superior to FA in evaluation of macular ischemia in cases of macular hemorrhage.

In our study, macular ischemia detected by FA had a negative relation with VA this was statistically significant. This result was consistent with Coscas $\boldsymbol{e t}$ $\boldsymbol{a l} .^{\left({ }^{(10)}\right.}$ but they did not find the same relation by OCT-A.

Wakabayashi et al..$^{(12)}$ and .Kang et $\mathrm{al}^{13}$ reported that ischemia in both SCP and DCP by OCT-A was negatively related with VA, and ischemia in the DCP having the stronger relation. Our study consistent with their study according to our standard of significant macular ischemia.

We found a negative relation between mean visual acuity and significant macular ischemia detected by OCT-A in the SCP, but without statistically significant difference.

This is explained by presence of another factor affected the VA which was the significant macular ischemia in DCP, this result confirms inability of SCP to evaluate macular ischemia alone and highlights the important role of DCP in detection of macular ischemia by OCT-A, especially when there is masking of retina by extensive hemorrhage which FA was not able to evaluate it and described it as undetermined type. 
In the current study, there was no difference between OCT-A and FA in detection of macular edema, both detected ME in all 10 cases (100\%)

We observed also that ME was present mainly in the DCP compared to SCP as reported by Spaide $\boldsymbol{e t}$ al. ${ }^{(\mathbf{1 4})}$ who reported that sites of macular edema are mainly localized in the DCP in regions of reduced or absent flow.

\section{CONCLUSION}

It could be concluded that OCT-A was superior to FA in detection of macular ischemia. Retinal ischemia in the DCP was more evident than that of SCP by OCT-A. . and OCT-A had stronger negative relation. In our study we stated a standard of significant macular ischemia detected by OCT-A. We demonstrated mathematically that $3 \times 3 \mathrm{~mm}$ OCT-A scan equal to 5 disc area by FA.

We observed that all ischemic cases by FA respect this standard and shows significant macular ischemia by OCT-A. this standard we explain the cause of decrease of VA in the cases that showed masking and could not be evaluate by FA. Description of retinal ischemia by this standard is more accurate.OCT-A has some side effects as its narrow field and the lack of dynamics present in FA such as leakage and AV transient time.We can say that OCT-A can replace FA in detection of retinal ischemia.

\section{RECOMMENDATIONS}

We recommend that larger studies should be performed with long term follow up to determine the prognostic value of OCT-A. In cases of BRVO with significant retinal hemorrhage, OCT-A can be done instead of FA. OCT-A can potentially replace FA when FA is contraindicated.

Larger studies should be performed to evaluate the standard area of macular ischemia and to classify significant ischemic versus non-ischemic BRVO, CRVO and other ischemic maculopathy.

\section{REFERENCES}

1. Cugati S, Wang JJ, Rochtchina E et al. (2006): Tenyearincidence of retinal vein occlusion in an older population:the Blue Mountains Eye Study. Arch Ophthalmol., 124:726-32.

2. Dithmar S, Hansen LL andHolz FG (2003): Retinal vein occlusions Ophthalmologe, 100:561-77.

3. Tsui I, Kaines A, Havunjian MA et al. (2011): Ischemic index and neovascularization in central retinal vein occlusion. Retina, 31:105-110.

4. Jia Y, Wei E, Wang X et al. (2014): Optical coherence tomography angiography of optic disc perfusion in glaucoma. Ophthalmology, 121:1322-1332.

5. Weinhaus RS, Burke JM, Delori FC et al. (1995): Comparison of fluorescein angiography with microvascular anatomy of macaque retinas. Exp Eye Res., 61:1-16.

6. Johnston R, Brucker AJ, Steinmann W et al. (1985): Risk factors of branchretinal veinocclusion. Arch Ophthalmol., 103:1831-1832.

7. Hayreh SS, Hayreh MS (1980): Hemi-central retinal vein occlusion.Pathogenesis, clinicalfeatures, and natural history. Arch Ophthalmol., 98:1600-1609.

8. Liu W, Xu L (2007): Vein occlusions in Chinese subjects. Ophthalmology, 114:1795-1796.

9. Hayreh SS, Klugman MR, Beri M et al. (1990): Differentiation of ischemic from non-ischemic central retinal vein occlusion during the early acute phase. Graefes Arch Clin Exp Ophthalmol., 228(3):201-217.

10.Coscas F, Glacet-Bernard A, Miere A et al. (2016): Optical coherence tomography angiography in retinal vein occlusion: Evaluation of superficial and deep capillary plexa. Am J Ophthalmol., 161:160-171.

11.Suzuki N, Hirano $\mathrm{Y}$, Yoshida $\mathrm{M}$ et al. (2016): Microvascular abnormalities on optical coherence tomography angiography in macular edema associated with branch retinal vein occlusion. Am J Ophthalmol., 161:126-132.

12. Wakabayashi T, Sato T, Hara-Ueno Cet al. (2017): Retinal microvasculature and visual acuity in eyes with branch retinal vein occlusion: imaging analysis by optical coherence tomography angiography. Invest Ophthalmol Vis Sci., 58(4):2087-2094.

13. Kang JW, Yoo R, Jo YH et al. (2016): Correlation of microvascular structures on optical coherence tomography angiography with visual acuity in retinal vein occlusion. Retina,37(9):1700-1709.

14.Spaide RF, Klancnik JM and Cooney MJ (2015):Retinal vascular layers imaged by fluorescein angiography and optical coherence tomography angiography. JAMA Ophthalmol., 133:45-50. 